Running head: SEXUAL HEALTH SEMINAR

\title{
'Where are all the men?’ A post-structural feminist analysis of a university's sexual health
} seminar

Margaret M. Quinlan, Ph.D.

University of North Carolina- Charlotte

Charlotte, NC

quinlan.margaret@gmail.com

Jennifer J. Bute, Ph.D.

Indiana University-Purdue University Indianapolis

Indianapolis, IN

jjbute@iupui.edu

This is an Accepted Manuscript of an article published by Taylor \& Francis Group in as “"Where are all the men?' A post-structural feminist analysis of a university's sexual health seminar” in Sex Education: Sexuality, Society and Learning on May 4, 2012, available online: http://dx.doi.org/10.1080/14681811.2012.677205 


\begin{abstract}
This case study explores a sexual health seminar offered at a Midwestern university. Using a poststructural feminist framework, we analyzed discourses from qualitative surveys, newspaper coverage, and participant observation. We argue that the framing of the seminar posed an obstacle to receiving healthcare, altercasted women in disempowering roles, and failed to acknowledge men’s voices. It is important to address entrenched gender biases, power imbalances, and assumptions that undermine students' retention of sexual health education and access to services. Based on this analysis, we developed recommendations for sexuality education of university students informed by feminist understandings of health.
\end{abstract}

Keywords: Sexuality education, poststructural feminism, gendered healthcare

This is an Accepted Manuscript of an article published by Taylor \& Francis Group in as “'Where are all the men?' A post-structural feminist analysis of a university's sexual health seminar” in Sex Education: Sexuality, Society and Learning on May 4, 2012, available online: http://dx.doi.org/10.1080/14681811.2012.677205 


\section{Introduction}

Scholars are increasingly drawing attention to gender biases in the framing of sexual and reproductive health issues and they are frequently framed as women's issues (Authors 2010). For instance, the Food and Drug Administration's delayed approval of the human papillomavirus vaccine for males, when a vaccine has been available to women since 2006, reified women’s roles in taking responsibility for matters of sexual health while simultaneously failing to engage men in critical discussions and practices (Thompson 2010). In addition, public conversations and press coverage of age-related infertility tend to discuss the experiences of women who have coped with the inability to get pregnant without accounting for the fact that men, too, have a biological clock and are involved in childbearing decisions (Authors 2010). These examples draw attention to the stubborn and persistent tendency to frame sexual and reproductive health as concerns for women, a practice that unfairly places the onus of responsibility on women to secure contraception and initiate conversations about safer sex and discourages the full engagement of men.

Our goal in this study is to add to the growing body of research that problematizes takenfor-granted assumptions about sexual health through an in-depth case study of an educational seminar at one Midwestern university. We position the seminar as another example of entrenched gender biases, power imbalances, and problematic assumptions that undermine sexual health education and access to crucial health services. In the following sections, we

This is an Accepted Manuscript of an article published by Taylor \& Francis Group in as "Where are all the men?' A post-structural feminist analysis of a university's sexual health seminar” in Sex Education: Sexuality, Society and Learning on May 4, 2012, available online: http://dx.doi.org/10.1080/14681811.2012.677205 
overview the need for sexual health education on college campuses, outline the theoretical assumptions that guided our study, and present our analysis of the seminar.

\section{Background}

Sexuality education in the United States is fraught with controversy (Askew 2007). There has been a long history in the US of colleges and universities attempting to address students' needs for sexual health. As early as the 1950s, academic departments and programs, such as Kinsey’s, have provided sexuality education (Irvine 2005). In the 1970s Lorna and Phillip Sarrel founded a program at Yale University that provided students with comprehensive sexual healthcare (Sarrel and Sarrel 1971). Although most debates surrounding sexuality education have centered on teaching primary and secondary school students about sex, public and private institutions of higher learning are not immune to the thorny debates enveloping this issue. Disagreement exists over the extent to which universities should be responsible for providing education about contraception and sexually-transmitted diseases (STDs) ${ }^{\mathrm{i}} /$ sexually transmitted infections (STIs) (Feigenbaum and Weinstein 1995). College students self-report that they frequently engage in unprotected sex while under the influence of alcohol or drugs (Dinger and Parsons 1999). According to 2006 estimates from the Centers for Disease Control and Prevention (CDC), young people ages 15 to 24 years account for only $25 \%$ of the sexually active population in the US but acquire nearly half of all new cases of STDs each year.

This is an Accepted Manuscript of an article published by Taylor \& Francis Group in as " "Where are all the men?' A post-structural feminist analysis of a university's sexual health seminar" in Sex Education: Sexuality, Society and Learning on May 4, 2012, available online: http://dx.doi.org/10.1080/14681811.2012.677205 
Even more striking is the self-reported lack of awareness about sexual health in this age group. A Kaiser Family Foundation (KFF) survey revealed "serious gaps” in knowledge about transmission and complications of STDs and efficacy of contraception. For example, one-sixth of adolescents and young adults assume that STD transmission cannot occur unless symptoms are visible, and many mistakenly believe that STD screenings are included in routine medical exams (Hoff et al. 2003). Critics have argued that students' inaccurate understanding of sexual health is the result of the recent focus on abstinence-only education in the US, a practice increasingly considered to be out of touch with the lives of adolescents and young adults. One recent study indicated that since the exponential growth in federal funding for abstinence-only education, the proportion of US teens receiving formal instruction about birth control methods has declined meaning students might arrive at college without adequate knowledge about sex (Lindberg, Santelli, and Singh 2006). Young people have themselves expressed a desire for more information about sexual health. According to the KFF survey, young people ages 15 to 24 are more concerned about sexual health issues than about any other health issue, and more than three-quarters of them want more information on sexual health topics. Yet, school-based sexuality education plays a small role in the lives of college-aged adults (Hoff et al. 2003).

Overall, numerous studies provide clear and compelling evidence that college students need and want sexuality education. But how can scholars, educators, and administrators address this need? This case study represents one step toward answering this question by presenting an analysis of a sexual health seminar. We analyzed discourses about this program from qualitative surveys, newspaper coverage, and participant observation to explore how the organizing of

This is an Accepted Manuscript of an article published by Taylor \& Francis Group in as "'Where are all the men?' A post-structural feminist analysis of a university's sexual health seminar" in Sex Education: Sexuality, Society and Learning on May 4, 2012, available online: http://dx.doi.org/10.1080/14681811.2012.677205 
healthcare resources is promoted or deterred through signifying practices. We maintain that the ideological underpinnings of the seminar often posed an obstacle to receiving healthcare, altercasted women in disempowering subject positions, and failed to acknowledge the relational nature of sexual health by disregarding men. Based on this analysis, we developed recommendations for sexuality education of college students informed by feminist understandings of health. We acknowledge that a nonfeminist or a feminist from a different perspective would have reached different conclusions. As with all interpretations, this account is partial and indeterminate.

\section{A Poststructural Feminist Framework}

Poststructural feminism (PF) has been used to examine issues of gender, power relations, language, and sexual health (Thompson 2010). PF theory was useful when examining the discourses surrounding the sexual health seminar, as it urges scholars to pay attention to the ways in which discourse shapes how we think, speak, and interpret the world (Weedon 1997). By examining the form and structure of the sexual health seminar through participant observation of the seminar, mediated newspaper discourse surrounding the seminar, and women's perceptions of the seminar in a web-based survey, we looked at how sexual health was constructed and defined through the sexual health seminar at this university. We examined the implementation of one health policy which (in)directly influenced the health and sexual practices of both men and women while questioning normative scripts and paying attention to how gendered bodies were discussed in the discourses. PFs acknowledge the power of language to shape our thoughts and

This is an Accepted Manuscript of an article published by Taylor \& Francis Group in as " Where are all the men?' A post-structural feminist analysis of a university's sexual health seminar" in Sex Education: Sexuality, Society and Learning on May 4, 2012, available online: http://dx.doi.org/10.1080/14681811.2012.677205 
realities and acknowledge that once discourse becomes normal or natural, they have the potential uphold structures of inequity (Weedon 1997). While analyzing the discourse, we sought to make sense of the ways in which language creates certain subject positions and disqualifies certain voices in order to offer into circulation alternative discourses that enlarge possibilities and ensure participatory processes. Based on these theoretical sensibilities, we sought to answer the following research question:

How do discursive practices define and construct sexual health, as seen through the sexual health seminar at this university?

\section{Research Practices}

We took a case study approach to the analysis of this seminar in order to empirically investigate this seminar in its real life context. We believe that case studies are rigorous pedagogical tools (Kimball 1995) and help to bring together theory and practice in ways that apply to everyday situations. To analyze the seminar's discursive practices, we obtained Institutional Review Board approval and collected discourses from three sources. First, a coauthor observed the seminar through participant observation. We supplemented the observations with a qualitative, web-based survey to gather university women's perceptions of the health seminar. Finally, we collected articles from campus and local newspapers to gain an understanding of the seminar's history and the debate surrounding the program. Thus, we brought together multiple discourses to give rise to a nuanced understanding of this sexual health seminar. In the following section, we outline the setting for our analysis by providing a brief

This is an Accepted Manuscript of an article published by Taylor \& Francis Group in as " Where are all the men?' A post-structural feminist analysis of a university's sexual health seminar" in Sex Education: Sexuality, Society and Learning on May 4, 2012, available online: http://dx.doi.org/10.1080/14681811.2012.677205 
history of the sexual health seminar, based on newspaper coverage and the experience of a coauthor, who attended the seminar in 2006.

Setting

The sexual health seminar was offered at a public Midwestern university of approximately 20,000 undergraduate and graduate students (51\% female and 49\% male). According to campus and local newspaper coverage, the university opened a gynecology clinic in 1970 and instituted the educational seminar in 1971 in response to a growing number of requests for information on sex and contraception $(1978 ; 1981 ; 1985)$. The program was pioneering at the time; the university was the first in the state to provide gynecological services to students (1978) and to offer group sessions on sexuality education (1985). From the seminar's inception in 1971 until its cancellation in 2008, attendance was required for women who wanted to receive a gynecological exam or a prescription for contraceptives at the campus health center (1972; 1973; 1978; 2007). Men were welcome to attend the sessions, and early notices in the campus paper referred to the session as "coeducational” (1972). However, there was no mechanism in place to require men's attendance. In a 2006 article, the campus health educator was reported as stating: "Men also are permitted to attend the seminar, though it changes the dynamics." Indeed, the vast majority of seminar participants were women $(1973 ; 1975 ; 1978 ; 2006)$. A waiver option was available for women who felt they had sufficient sexual health information. Campus health educators repeatedly stressed that the main thrust of the session was to provide information because many students had misconceptions about sex (1973; 2006). As times changed, campus officials updated the seminar (e.g., the term "venereal diseases" changed first to "STDs" and

This is an Accepted Manuscript of an article published by Taylor \& Francis Group in as " "Where are all the men?' A post-structural feminist analysis of a university's sexual health seminar" in Sex Education: Sexuality, Society and Learning on May 4, 2012, available online: http://dx.doi.org/10.1080/14681811.2012.677205 
later to "STIs.") The seminars took place at the health center (1984) and originally lasted an hour and a half but in the 1980s were expanded to a two-hour session (1978; 1985; 2006; 2007). Sessions were available several times a week and were typically taught by a registered nurse, a gynecologist, or the campus health educator (1972; 1975; 1977).

When the co-author attended this seminar in 2006, it was taught by a graduate student in the health promotion office. The seminar lasted two hours, with approximately 15 female participants and no men. Topics covered included contraceptives (e.g., birth control options, a condom demonstration), STIs (e.g., images of infections, information about transmission), what to expect when having a pap smear, how to conduct breast exams, and questions to ask a gynecologist.

Although the sexual health seminar was groundbreaking in the early 1970s, the seminar became a source of controversy in recent years. A major complaint from students was the program's focus on educating women but not men (2001; 2004; 2006). Some students argued that the seminar was offensive and discriminatory because of its primary focus on educating women and because men did not have to attend a seminar before receiving healthcare (2006; 2007). Students voiced concerns about difficulty obtaining waivers and the limited availability of seminar sessions (2004; 2006). In 2006, a group of graduate students made formal complaints to campus administrators, focusing on the fact that only women were required to complete the session. Subsequently, a nine-member committee was formed to evaluate the program (2007) and they suggested a number of changes, including communication to inform students about their options regarding the sexual health seminar (e.g., the waiver option), updated sexual health

This is an Accepted Manuscript of an article published by Taylor \& Francis Group in as " "Where are all the men?' A post-structural feminist analysis of a university's sexual health seminar" in Sex Education: Sexuality, Society and Learning on May 4, 2012, available online: http://dx.doi.org/10.1080/14681811.2012.677205 
information on the health center website, and easier access to the seminar's schedule. The committee also recommended a number of format changes to the program, including holding separate seminars for students wanting an annual gynecological exam and those wanting a contraceptive prescription, offering the seminar at times more compatible with students' schedules, evaluating the seminar with the input of graduate students from health-related academic programs, and offering a gender-inclusive format that would make it more useful to men (2007). As of 2012, the sexual health seminar has been eliminated; currently no mandatory sexual health program is offered at the university. Although no formal announcement was made about discontinuing the seminar, an April 2008 article in the campus newspaper hinted that the program might be reinstated in the near future. The announcement stated: "Until this year, students seeking gynecological services at [health center] for the first time were required to attend a two-hour sexual health seminar. Amid complaints and diminishing numbers of attendees, Health Promotions temporarily discontinued the sessions.”

\section{Female College Students’ Perceptions of the Seminar}

The web-based portion of this study gathered information about female students’ understandings of the seminar. The surveys were anonymous with any identifying information automatically inserted by the software deleted before analysis, and the data cases were scrambled to more fully protect anonymity. Participation in our study was voluntary; students had to accept our electronic informed consent form to take part in this study. As part of a larger study examining gynecological health and privacy, a subsample of female students answered a series of questions about the seminar, including their knowledge of and personal experiences with the

This is an Accepted Manuscript of an article published by Taylor \& Francis Group in as “"Where are all the men?' A post-structural feminist analysis of a university's sexual health seminar” in Sex Education: Sexuality, Society and Learning on May 4, 2012, available online: http://dx.doi.org/10.1080/14681811.2012.677205 
seminar. To access our sample, we used the university’s e-mail list of 9,690 female

undergraduate and graduate students. From this list, 1,000 were randomly selected to receive two follow up e-mails.

The final sample included 42 women ranging in age from 18 to 45. Most respondents ( $n$ = 36) were between the ages of 18 and 26; 4 students were between the ages of 27 and 30, and 2 students were over the age of 40 . Thirty-three students were undergraduates, and 9 were graduate students. Thirty-five students described themselves as Caucasian, two described themselves as African American, and two described themselves as Caucasian/Native American. One participant described herself as Asian/Pacific Islander, one described herself as Caucasian/Latina, and one described herself as international. The majority of participants $(n=30)$ reported having health insurance coverage through a parent or guardian's insurance plan. Nine students had coverage through the university health insurance plan. Two reported coverage through personal health insurance, and one had insurance coverage through a significant other's plan. Although the relatively small number of women who responded to the open-ended portion of the survey would be problematic if we were trying to make generalizable claims, the response rate is appropriate for in-depth analysis of qualitative data, such as the responses women provided to the openended questions (Patton 1990). Instead of being interested in claims of frequency, we were more interested in how individuals described their experiences and in the practical implications of these experiences.

Newspaper Reports of the Seminar

This is an Accepted Manuscript of an article published by Taylor \& Francis Group in as "“Where are all the men?' A post-structural feminist analysis of a university's sexual health seminar" in Sex Education: Sexuality, Society and Learning on May 4, 2012, available online: http://dx.doi.org/10.1080/14681811.2012.677205 
In addition to using the survey, we collected newspaper articles and editorials by using Lexis-Nexis and America's Newspapers and by searching the archives of the campus health center, the university newspaper, and the two local newspapers. The key search terms we used when searching the databases and archives were sex, health center, seminar, birth control, and gynecology. We collected and analyzed a total of 30 newspaper articles that mentioned the seminar or focused on the seminar published between 1971 (the year the seminar began) and 2008 (the year the seminar ended).

\section{Participant Observation}

One of the co-authors, was a graduate student at the time the study took place, participated in the seminar in order to receive her annual examination. Guided by her feminist sensibilities, the she took fieldnotes throughout the seminar noting the tone, language used to discuss sexual health, emotions she experienced, attendees, student involvement, and content covered.

\section{Data Analysis}

We used an iterative process to analyze women's qualitative responses to the survey, public discourse in the news articles, and the co-author's fieldnotes using thematic analysis, a method that focuses on identifying patterned themes in the data. We drew on the assumptions of PF outlined in our theory section as sensitizing concepts (Patton 2002). Based on our theoretical sensibilities, we engaged in open coding (Strauss and Corbin 1990) by reading through the entire corpus of news clippings, fieldnotes, and qualitative survey responses to develop an initial set of recurring themes to describe reactions to the seminar. We began our analysis by separately

This is an Accepted Manuscript of an article published by Taylor \& Francis Group in as " "Where are all the men?' A post-structural feminist analysis of a university's sexual health seminar” in Sex Education: Sexuality, Society and Learning on May 4, 2012, available online: http://dx.doi.org/10.1080/14681811.2012.677205 
reading the survey responses and gleaning a general sense of respondents' reactions to the sexual health seminar (e.g., did they view it positively?). The co-author who observed the seminar also noted whether her experience in the seminar was similar to or different from participants' experiences. We then followed a constant comparative method (Strauss and Corbin 1990) in which we compared our initial categories against one another to narrow and define the categories. For example, we noted that women's descriptions of feeling that they were belittled or patronized by the language used in the seminar were distinct from women's reflections that they were upset that men did not have a similar requirement. We then (re)read the survey data and began verifying these recurring themes. As we continued to collect and analyze newspaper articles, we re-evaluated and refined the themes, arguments, and concepts we had identified in our initial analysis. After meeting to agree on our final set of categories, we returned to the data independently to test the categories. We met again to discuss any discrepancies or disagreements. Along the way, we ensured the trustworthiness of our data by creating an audit trail of theoretical memos and meeting notes (Strauss and Corbin 1990).

We then layered together themes from the participants' stories, the newspaper articles, and participant observation to build a nuanced and complex representation of multiple understandings of the sexual health seminar, including the perspectives of campus officials and students. Finally, we selected the representative excerpts from student responses and news stories to illustrate and illuminate the major themes. Throughout this iterative process, we met regularly to discuss our impressions of the data and to sharpen our understanding of the discourse. Despite our efforts to recognize and acknowledge multiple voices, we understand that how the seminar

This is an Accepted Manuscript of an article published by Taylor \& Francis Group in as “"Where are all the men?' A post-structural feminist analysis of a university's sexual health seminar” in Sex Education: Sexuality, Society and Learning on May 4, 2012, available online: http://dx.doi.org/10.1080/14681811.2012.677205 
was discussed in the newspaper articles and women's responses to the seminar in the web-based survey may not reflect the perspectives of all parties at the university. We acknowledge that our sensitizing concepts led us to a particular interpretation of the data.

Results

\section{Patterns of (In)Accessibility to Sexual Health Seminar}

We begin our results section by summarizing general patterns from the sample of 42 women who responded to the survey. Ten of the 42 women had attended the seminar. Nine of the 42 women were familiar with the seminar but had never attended it, though they had opinions on the seminar that they expressed in the survey. Some women were well aware of the seminar but refused to attend it because they disagreed with the approach, the requirement for women, or both. Twenty-three women indicated that they had never heard of the seminar or did not know that it existed. Thus, over half the sample of this potentially high-risk population had neither knowledge of the seminar nor access to the information presented. We believe that the fact that many women in the sample did not know about the seminar is an important piece of information and reflects a perhaps well-intentioned but not highly successful attempt to get important health information to college students. The following sections are based on an in-depth analysis of the discourses about the seminar. Summary of Survey Respondents’ Impressions of the Seminar

Nineteen of the women surveyed provided open-ended comments about the sexual health seminar. Ten of these women had attended the seminar and nine knew about, but had never

This is an Accepted Manuscript of an article published by Taylor \& Francis Group in as "Where are all the men?' A post-structural feminist analysis of a university's sexual health seminar” in Sex Education: Sexuality, Society and Learning on May 4, 2012, available online: http://dx.doi.org/10.1080/14681811.2012.677205 
attended, it. We characterized women's evaluative comments as negative, neutral, positive, or mixed (e.g., a combination of positive and negative comments). Nine women had a negative impression of the seminar. For instance, one of these women stated, "I think requiring a female student to attend a seminar in order to have gyn services is DUMB.” Three women responded with neutral comments that described the seminar but did not evaluate it in a specific way (e.g., "It was a small group setting. The girl who led it went over the basics of birth control and what would go on when we had the exam.”). Two women who had attended the seminar had positive reactions. One woman said, "It was actually really informative. I think that there are things in that seminar that every woman should know, even if she isn’t taking birth control... Overall, very good.” The remaining five women described mixed reactions to the seminar. One woman said, “Not bad but too long. It didn’t teach me anything new but reinforced things I may have forgotten... needs to be more updated, funny, and entertaining with more real life situations and experiences.”

Themes in the Discourse about the Sexual Health Seminar

The discourse surrounding the sexual health seminar, based on voices in the responses, newspaper coverage, and participant observation, reveals a greater understanding of the controversies and tensions that enveloped the program. We identified three primary themes: (a) conflicting understandings about the whether the purpose of the seminar was educational or just an obstacle to healthcare, (b) the altercasted subject positions of female university students (who do they think we are?), and (c) the exclusion of men's voices (where are all the men?).

This is an Accepted Manuscript of an article published by Taylor \& Francis Group in as "Where are all the men?' A post-structural feminist analysis of a university's sexual health seminar” in Sex Education: Sexuality, Society and Learning on May 4, 2012, available online: http://dx.doi.org/10.1080/14681811.2012.677205 
Obstacle or educational? One of the most problematic themes illuminated in the discourse is the framing of the seminar as a prerequisite or, in some cases, an obstacle to receiving adequate and appropriate healthcare. Newspaper coverage of the seminar indicated that since its inception in the 1970s, students have viewed the program as an inconvenience. When asked what they knew about the university’s sexual health seminar, some survey respondents described the session as a hoop they had to jump through to access gynecological care or prescription contraceptives. Such responses included statements like, "I know that you must attend it before you are able to get a gynecological exam at [the health center]"; "I believe this is the class I had to attend in order to be referred for a pap smear and exam”; "You have to attend to get birth control from the [health center] pharmacy"; and "This is the seminar that you need to attend before they give you birth control.” The language in each of these statements reflects the perceived power of the university to compel women to attend the session before receiving healthcare.

In some extreme cases, women in the survey sample described the seminar as an obstacle that prevented, or nearly prevented, them and others from receiving care at the university health center. One woman commented that the seminar's inconvenient schedule almost prevented her from seeking care at the health center:

The seminar was only offered at specific times, which did not coincide with our class schedule. Fortunately, a special one-time-only seminar was held for us in order to fulfill the requirement. If I had another commitment on that evening, I would be prohibited from receiving annual exams at [the health center]. Adult women should not be precluded

This is an Accepted Manuscript of an article published by Taylor \& Francis Group in as “"Where are all the men?' A post-structural feminist analysis of a university's sexual health seminar” in Sex Education: Sexuality, Society and Learning on May 4, 2012, available online: http://dx.doi.org/10.1080/14681811.2012.677205 
from receiving such important and easy preventative care simply because of scheduling conflicts. Their health is too important!

In some cases, women sought healthcare outside the university system so that they could avoid the seminar altogether. One woman explained, "I thought that was a huge hindrance to my obtaining birth control. So I stayed away from [the university's] gynecological services.... Don’t make it a prerequisite to visit the gynecologist at the health center.” Likewise, another woman was so offended by the program that she, too, avoided the university's clinic:

I am personally offended that I am required to attend the seminar when I do not wish to see a gynecologist for birth control. This has prevented me from receiving gynecological services at [the university] for the 5 years I have been enrolled in graduate school.

In one troubling case, a woman described a situation in which her sister-in-law was denied vital health services at the university clinic because she had not attended the seminar:

My sister-in-law was having a reproductive health emergency, but she was not allowed to go see a gynecologist until she had attended the seminar. While I'm sure the seminar is held for good reasons, there are certain occasions when it is not appropriate to keep a woman from seeing her doctor because she hasn’t sat through a talk about condoms. Though somewhat exceptional, this example illustrates the material and corporeal consequences of a seminar requirement that reinforces dominant power structures and impedes access to healthcare.

In interviews with reporters, health education staff members at the university admitted that many students found the seminar to be a hassle, yet they defended the educational goals of

This is an Accepted Manuscript of an article published by Taylor \& Francis Group in as " "Where are all the men?' A post-structural feminist analysis of a university's sexual health seminar" in Sex Education: Sexuality, Society and Learning on May 4, 2012, available online: http://dx.doi.org/10.1080/14681811.2012.677205 
the session. One official stated, “A lot of women think they know everything, and they don’t.” She went on to explain that she has never had a woman tell her that the class was not worthwhile. Though one could argue that college students need sexual health education (see the KFF survey) this statement from a campus health official reinforces sexist ideologies and institutional patriarchy by framing “women” (but not men) as being ignorant about their own health, when indeed both men and women have information to learn regarding sexual health.

Overall, women in the sample, including those we refused to attend the seminar, tended to frame the sexual health seminar as a prerequisite that in some cases inhibited them from receiving needed or desired health services, including regular gynecological exams, pap smears, and prescriptions for contraceptives. Despite the best intentions of campus officials, the educational goals of the seminar are de-emphasized, and hegemonic power structures are perpetuated when discursive practices frame the session as a precondition or a hindrance rather than an informative and useful program.

Who do they think we are? Another thee highlighting the general discontent with the seminar underscores the ways in which some women felt altercasted into particular subject positions by the nature of the session and discourse used in the seminar. Although campus officials repeatedly indicated that the intent of the seminar was to empower women by giving them information (1985; 2001), women did not necessarily feel empowered by the session, as they were cast into particular subject positions. In fact, some women found the seminar insulting and felt it altercasted them as unknowledgeable and even sexually promiscuous. Women in the survey sample described the session as offensive and demeaning. One woman said, "My

This is an Accepted Manuscript of an article published by Taylor \& Francis Group in as “"Where are all the men?' A post-structural feminist analysis of a university's sexual health seminar” in Sex Education: Sexuality, Society and Learning on May 4, 2012, available online: http://dx.doi.org/10.1080/14681811.2012.677205 
perception is that it is completely unnecessary and somewhat degrading to [university] women to require them to attend such a seminar prior to receiving services.” Another woman added, "It reminded me of the $5^{\text {th }}$ grade sex talk. I hate being talked to like I'm a small child, especially regarding my reproductive health.” The co-author shared these women's sentiments, as the graduate student who ran the seminar was younger than she and made comments like "you girls,” and "you young girls.” At times, the co-author felt that the graduate student running the seminar talked to the women attending the seminar from a punitive standpoint as if all they did on the weekend was engage in promiscuous activities. The co-author recognizes that the experience at the seminar may have been different if the seminar had been run by an experienced health professional.

Several respondents felt that the requirement to attend the session assumed that they were uninformed about sexual and reproductive health. The woman who had received a waiver from her physician described herself as being "THRILLED” that she did not have to attend the program. She stated:

I'm old enough now that I don’t need a lecture on having safe sex, STDs, and how to take my birth control pills. The doctor quizzed me on the side effects of birth control pills, STD transmission, and the like, and coupled with the fact that I'm in a long-term monogamous relationship, felt that I had sufficient knowledge of the matters that would be discussed in the seminar.

This female student indicated that she had engaged in a conversation with her personal doctor and did not need to attend the seminar. Similar to the co-author who attended the seminar, this

This is an Accepted Manuscript of an article published by Taylor \& Francis Group in as “"Where are all the men?' A post-structural feminist analysis of a university's sexual health seminar” in Sex Education: Sexuality, Society and Learning on May 4, 2012, available online: http://dx.doi.org/10.1080/14681811.2012.677205 
woman was insulted by the assumption that all women are sexually promiscuous. Other women agreed that their knowledge of sexual health should preclude their attendance (although only the woman quoted above commented on her efforts to get a waiver). One woman said:

I feel as though I should not have to attend a seminar before I can see a doctor. I am a senior in college and have taken many health courses, and I feel as though I don't need someone to tell me about safe sex, STIs, or pregnancy.

Another woman echoed this sentiment: "By the age of 18 years, I believe most women know the content of the seminar already, and if not, they should be offered the option of attending such a seminar but not required to do so.” This woman’s statement indicates her lack of knowledge about the waiver option for women.

Newspaper coverage of the seminar included statements from students who felt that the seminar taught them nothing new. One woman said, "I had to waste two hours listening to this student tell me a bunch of stuff I already knew about.” Although studies reviewed in the rationale for this manuscript suggest that many college-aged people need and desire sexual health information, some women in this study felt that they already possessed adequate knowledge. In a 2006 newspaper article, the campus health educator defended the seminar by explaining that the changing nature of medical information necessitated such a requirement: "No matter who attends or what they already know, they're going to leave with at least some new information.” However, the discursive practices used to promote and present the information in the seminar functioned to reproduce dominant power structures that implied that the university “knew best,” causing women to feel degraded, insulted, and offended. In essence, the educational

This is an Accepted Manuscript of an article published by Taylor \& Francis Group in as "Where are all the men?' A post-structural feminist analysis of a university's sexual health seminar” in Sex Education: Sexuality, Society and Learning on May 4, 2012, available online: http://dx.doi.org/10.1080/14681811.2012.677205 
purpose of the seminar, which might have been well-intentioned, was poorly executed according to PF standards.

Other women felt that the seminar and its tone positioned all women who attended as sexually active or even promiscuous, thus overlooking issues relevant to abstinent women or women in monogamous relationships. One respondent explained:

The presenters seem to be targeting promiscuous unmarried women who spend every weekend getting drunk and having sex, and that it does not even consider that many of the women in attendance would be insulted by such assumptions because they might not be sexually active.

Another woman agreed, stating, "I think the seminar is designed to assume that the participant is already sexually active and does not acknowledge abstinence at all. In fact, for the abstinent listener, it almost makes you feel like an outsider.” Again, some women felt that the patronizing content and the tone of the seminar excluded and demeaned them as they felt that categories and assumptions were predetermined about their sexual activity.

Finally, nontraditional students and graduate students felt that their educational needs, which may differ from those of traditional undergraduates, were ignored by the seminar. One nontraditional student said:

In order to be referred from the clinic for my pap smear and exam, I had to take a 2-hour class that was designed [for] and addressed to undergraduate students in their early twenties. The nurse leading the class repeatedly addressed members of the class as "you young women,” despite the fact that I was older than her. The information presented was

This is an Accepted Manuscript of an article published by Taylor \& Francis Group in as “"Where are all the men?' A post-structural feminist analysis of a university's sexual health seminar” in Sex Education: Sexuality, Society and Learning on May 4, 2012, available online: http://dx.doi.org/10.1080/14681811.2012.677205 
inappropriate for a woman in her 40s who has had children and is in a stable, long-term relationship.

As this nontraditional student implied, she did not feel that her sexual health needs were taken into consideration. Also, it appeared that as a woman in her 40s, she felt excluded by the content covered, as her body and reproductive needs were not addressed. Indeed, the exclusion of certain female bodies (e.g., nontraditional students) (re)inscribes hegemonic patterns and practices regarding who is "allowed" or "permitted” to be sexually active at this university.

Where are all the men? Another recurring theme in the discourse that reveals the anger and frustration felt by some women was the lack of a similar educational requirement for men. As one woman said, "Requiring female students to attend a seminar before providing gynecological services is discriminating against women. Men can have their reproductive organs examined without taking a seminar, why can’t females?” Several women noted that the requirement meant that women had to continue shouldering the burden of pregnancy and STI prevention:

It kind of upsets me, though, that guys on campus don’t have to attend. I know they have no reason to, because they don't take birth control, but it seems like women have to be almost entirely responsible for preventing the spread of disease and unwanted pregnancy. I think guys should be held more accountable somehow, though I don't have any recommendations for how.

We see in this reflection one of the ways in which men's voices and experiences were disqualified and silenced, while dominant ideologies that frame women as responsible for sexual

This is an Accepted Manuscript of an article published by Taylor \& Francis Group in as "Where are all the men?' A post-structural feminist analysis of a university's sexual health seminar” in Sex Education: Sexuality, Society and Learning on May 4, 2012, available online: http://dx.doi.org/10.1080/14681811.2012.677205 
and reproductive health were reinforced. One student commented on the relational nature of sexual health:

I feel as though the seminar is unfair as well. Why should women have to attend a seminar before they are able to get a prescription for birth control, whereas men do not have to? In a healthy relationship it is as much the man's as it is the woman's responsibility to provide birth control (that protects against STI’s as well as pregnancy).”

And another woman pointed out that men, too, need knowledge of sexual health:

I have also heard it said that it would make a lot more sense, and I agree with this, to have some type of seminar on birth control geared towards men. Most men know next to nothing on the topic, and leave the responsibility too much in the hands of women.

The absence of a similar requirement for men was noted in newspaper coverage of the seminar. In a letter to the editor published in the campus paper, one student wrote, "Women should bear all the responsibility for birth control and avoiding STDs. This is, after all, the 21st century.” Male students quoted in various news pieces expressed concern about the educational needs of both men and women. One man described the requirement for women to attend the seminar as “offensive.” Another male student explained "I see how it’s important for all guys to know this stuff. We need to learn to be responsible, too.”

Campus officials defended the requirement for women. The health educator emphasized that men were welcome to attend the seminar but explained that campus officials were opposed to a university-wide reproductive health education requirement:

This is an Accepted Manuscript of an article published by Taylor \& Francis Group in as “"Where are all the men?' A post-structural feminist analysis of a university's sexual health seminar” in Sex Education: Sexuality, Society and Learning on May 4, 2012, available online: http://dx.doi.org/10.1080/14681811.2012.677205 
I wish there was a mechanism that we could use to require men to learn about reproductive health, because whether you're sexually active or not, things can go wrong.... many college-aged men are not informed about important aspects of their reproductive health, including testicular cancer. Currently there is no way to reach all of them.

As this quotation illustrates, institutional practices suggested that there was no way to require a similar seminar for men, once again drawing our attention to the power of institutions to define subject positions, including who has access to healthcare and information and who is held responsible for sexual and reproductive health. This discourse not only draws attention to the absence of a requirement for men, it highlights men's needs for information about their own sexual and reproductive health. One student explained, "Not only are men left in the dark about their own health, but it places the responsibility of birth control on the women.”

\section{Discussion and Implications}

We acknowledge that college students need credible information about sexual and reproductive health and sympathize with campus officials who tackle the challenge of providing this information. Nevertheless, our investigation suggests a plethora of dilemmas surrounding one university's approach to sexual health education. Educators and practitioners interested in teaching college students about sexual health can use our case study to understand and avoid the entrenched gender biases, power imbalances, and assumptions that undermined students' retention of information and access to services.

This is an Accepted Manuscript of an article published by Taylor \& Francis Group in as " "Where are all the men?' A post-structural feminist analysis of a university's sexual health seminar" in Sex Education: Sexuality, Society and Learning on May 4, 2012, available online: http://dx.doi.org/10.1080/14681811.2012.677205 
Our analysis revealed three problematic issues. First, making the seminar a prerequisite to accessing care at the university health center de-emphasized the educational goals of the program and (re)inscribed the university's power to determine access to healthcare. By positioning women as ignorant about sexual health, implying that women were sexually promiscuous, and failing to meet the needs of various audiences, the discursive practices of the seminar put many women on the defensive. Hegemonic and patriarchal practices reflected the power of university officials and the relative powerlessness of women. Finally, the absence of a similar requirement for men was a major source of controversy. By making the seminar a requirement for women, campus officials not only reified women's roles as sole protectors against pregnancy and STIs, they also reinforced heterosexist ideologies and denied men access to information about their own health. Although the seminar may have been well-intentioned and was originally designed to meet the needs of students who requested sexual health information, the seminar's execution and the discursive practices used to present information and to promote the program were ultimately problematic.

\section{Practical Implications}

Based on our examination of the sexual health seminar and feminist approaches to healthcare, we offer suggestions to inform the development of future programs. Our analysis concludes that this seminar had the potential to benefit students and did not need to be dismantled forever. Thus, current and future educators on college campuses can learn from the mistakes made in this seminar. They can transform responsibility for sexual health by including students in the process as they re-envision ways of teaching sexual health topics and by

This is an Accepted Manuscript of an article published by Taylor \& Francis Group in as " "Where are all the men?' A post-structural feminist analysis of a university's sexual health seminar" in Sex Education: Sexuality, Society and Learning on May 4, 2012, available online: http://dx.doi.org/10.1080/14681811.2012.677205 
acknowledging that men have a stake in sexual health issues. Educators must ensure that all students have equal access to sexual health information and that educational requirements do not prevent students from accessing vital healthcare. Universal access to quality healthcare and information is a hallmark of feminist principles. However, as our analysis reveals, simply offering (or requiring) health information is not sufficient.

Information must be presented in nonthreatening and nonstigmatizing ways and must meet the needs of diverse student populations, including students with different levels of sexual health knowledge, abstinent students; men; lesbian, gay, bi-sexual, transgendered, queer/questioning (LGBTQ) students; and nontraditional students. There is no question that women bear significant physical, emotional, and public burdens related to sexual and reproductive health. We agree that women should actively participate in healthcare, but we also believe that educators enable men's lack of involvement when they neglect to expect a proactive, partnered engagement. Instead of finding ways to address men's sexual and reproductive health in the seminar (after over thirty years), authorities dismantled the seminar. If society continues to expect women to be responsible, but fail to expect the same for men, we enable the ignorance of men in regard to their own and their partners' sexual health. For us, this begged the questions, "Was this university not ready to address men's sexual health?" "Was it the path of least resistance to terminate the seminar rather than hold men responsible and accountable for being educated about sexual health?” Perhaps gender biases were so deeply rooted in the structure of this university that the university was unable to rethink its approach to educating students about

This is an Accepted Manuscript of an article published by Taylor \& Francis Group in as " "Where are all the men?' A post-structural feminist analysis of a university's sexual health seminar" in Sex Education: Sexuality, Society and Learning on May 4, 2012, available online: http://dx.doi.org/10.1080/14681811.2012.677205 
sexual health. In this instance, with a persistent focus on the female body, authorities continued to dismiss the interactive role of men in matters of sexual and reproductive health.

As educators draw lessons from our case study, we also encourage them to pay attention to cutting edge research in sexuality education that suggests teaching students to access sexual pleasure, a topic that was conspicuously absent in the seminar we observed (Fine 1988; Tolman 2002), but that has the potential to increase young people's care for their bodies. Askew (2007) found success in designing a feminist-informed sexuality education course in which she framed sexual health in terms of desire, pleasure, and empowerment. This approach enhanced students' sexual development, and students who completed her course expressed greater confidence in as sexual beings in addition to gaining increased knowledge of sexual health. Additionally, we urge health educators to look at sexuality education outside the US (Northern Europe, Africa, Asia, etc.) for insight into how to help individuals develop into sexually healthy adults. Sexual health educators must address sexual coercion, violence and victimization on college campuses, an extremely important topic that was not addressed in the seminar. For example, in one study of undergraduate students, Frazier et al. (2009) found that $27 \%$ of women reported unwanted or uninvited sexual attention and 5\% reported unwanted sexual contact in adulthood.

Finally, rather than treating women as being ignorant about sexual and reproductive health, educators could focus on validating students’ knowledge and experiences and perhaps engage them as co-creators of programs. With student input, seminar designers could build on feminist practices such as networking and collaboration in order to address some of the inequalities and inadequacies of the seminar. Co-creators could survey what male and female

This is an Accepted Manuscript of an article published by Taylor \& Francis Group in as “"Where are all the men?' A post-structural feminist analysis of a university's sexual health seminar” in Sex Education: Sexuality, Society and Learning on May 4, 2012, available online: http://dx.doi.org/10.1080/14681811.2012.677205 
students want and need to learn about sexuality education, which may decrease perceptions of the punitive nature of sessions like this seminar. Rather than have a seminar be a requirement for female students, administrators should find a way to make the seminar a requirement for all students. Not attending the seminar need not impact access to healthcare services. Co-creators could also design seminars for different populations (e.g., graduate students, students with children). We believe co-creators will allow for a more dialogic format rather than the hierarchical approach to sexuality education that existed at this university. We shared the results of this analysis with the current health educator formerly responsible for the seminar. We felt called to action by the voices of students and believe that if the sexual health seminar is reinstated, the revamped program will benefit from the analysis presented here.

Although our examination of the sexual health seminar offers valuable lessons for health educators, we acknowledge that some challenges are beyond the scope of our analysis. Implementing a mechanism that ensures college students' universal access to sexual health information requires time and resources not available on all campuses. Nevertheless, our analysis of the controversies and tensions facing this particular program should be useful to students and officials. As feminist scholars interested in sexual health issues, we urge other scholars to pay attention to normative sexual scripts and to question language and practices that inform sexual health policies.

This is an Accepted Manuscript of an article published by Taylor \& Francis Group in as “"Where are all the men?' A post-structural feminist analysis of a university's sexual health seminar” in Sex Education: Sexuality, Society and Learning on May 4, 2012, available online: http://dx.doi.org/10.1080/14681811.2012.677205 


\section{References}

Askew, Julie. 2007. Breaking the taboo: An exploration of female university students’ experience of attending a feminist-informed sex education course. Sex Education 7: 251264.

Center for Disease Control and Prevention. 2006. STD Surveillance 2006. http://www.cdc.gov/std/stats/adol.htm

Dinger, Mary K., and N. Parsons. 1999. Sexual activity among college students living in residence hall and fraternity or sorority housing. Journal of Health Education 30: 242246.

Feigenbaum, Rhona, and Estelle Weinstein. 1995. College students’ sexual attitudes and behaviors: Implications for sexuality education. Journal of American College Health 44: 112-118.

Fine, Michelle. (1988). Sexuality, schooling and adolescent females: The missing discourse of desire. Harvard Educational Review 58: 29-51.

Frazier, P., Anders, S., Perera, S., Tomich, P., Tennen, H., Park, C., \& Tashiro, T. (2009). Traumatic events among undergraduate students: Prevalence and associated symptoms. Journal of Counseling Psychology 56: 450-460.

Hoff, Tina, Liberty Greene, and Julia Davis. 2003. National survey of adolescents and young adults: Sexual health knowledge, attitudes, and experiences. Menlo Park, CA: Kaiser Family Foundation.

This is an Accepted Manuscript of an article published by Taylor \& Francis Group in as "Where are all the men?' A post-structural feminist analysis of a university's sexual health seminar” in Sex Education: Sexuality, Society and Learning on May 4, 2012, available online: http://dx.doi.org/10.1080/14681811.2012.677205 
Kimball, Bruce A. (1995). The emergence of case method teaching, 1970-1990s: A search for legitimate pedagogy. The Poyneter Center for the Study of Ethics and American Institutions, Indiana University.

Irvine, Janice M. 2005. Disorders of desire: Sexuality and gender in modern American sexology. Philadelphia, PA: Temple University Press.

Lindberg, Laura D., John S. Santelli, and Susheela Singh. 2006. Changes in formal sex education: 1995-2002. Perspectives on Sexual and Reproductive Health 38: 182-189. National Center for Education Statistics. http://nces.ed.gov/programs/coe/2002/analyses/nontraditional/sa01.asp

Patton, Michael Q. 1990. Qualitative evaluation and research methods 2nd ed. Thousand Oaks, CA: Sage.

Sarrel, Phillip M., and Lorna J. Sarrel. 1971. A sex counseling service for college students. American Journal of Public Health 61: 1341-1347.

Strauss, Anselm and Juliet Corbin. 1990. Basics of qualitative research: Grounded theory and procedures and techniques. Newbury Park, CA: Sage.

Thompson, Marie. 2010. Who’s guarding what?: A poststructural feminist analysis of Gardasil discourses. Health Communication 25: 119-130.

Tolman, Deborah L. 2002. Dilemmas of desire. Cambridge, MA: Harvard University Press. Weedon, Chris. 1997. Feminist practice and poststructural theory, $2^{\text {nd }}$ ed. Oxford, UK: Basil Blackwell.

This is an Accepted Manuscript of an article published by Taylor \& Francis Group in as “"Where are all the men?' A post-structural feminist analysis of a university's sexual health seminar” in Sex Education: Sexuality, Society and Learning on May 4, 2012, available online: http://dx.doi.org/10.1080/14681811.2012.677205 
i We use the term "STD” rather than "STI” when referencing reports because the reports from the CDC (2006) and the KFF (2003) use the term "STD.”

This is an Accepted Manuscript of an article published by Taylor \& Francis Group in as “"Where are all the men?' A post-structural feminist analysis of a university's sexual health seminar” in Sex Education: Sexuality, Society and Learning on May 4, 2012, available online: http://dx.doi.org/10.1080/14681811.2012.677205 